\title{
DEFECTIVE WARNINGS, REMOTE CAUSES, AND BANKRUPTCY: COMMENT ON SCHWARTZ
}

\author{
ROBERT D. COOTER*
}

\begin{abstract}
A
s a jury may have twelve members, a lawyer likes to present at least twelve plausible arguments. There being one standard of mathematical truth, an economist is reluctant to make an argument publicly until it is tight. Alan Schwartz's paper "Products Liability, Corporate Structure, and Bankruptcy: Toxic Substances and the Remote Risk Relationship" is replete with novel ideas. He makes many plausible arguments, which I will not summarize, and a few tight ones, which I will make tighter. Identifying the actual or possible foundations of his paper yields some surprising theoretical conclusions and confirms some familiar ones, and these conclusions have implications for the current policy debate about inherently dangerous products.

This paper is divided into four sections. Section I describes the technology and the institutional setting for a model of inherently dangerous products. Schwartz analyzes the incentives of manufacturers to invest in research on the dangerousness of products, and he assumes that their findings are issued in accurate warnings. In contrast, this paper assumes that manufacturers of inherently dangerous products are free to vary the severity of the warnings issued to buyers in light of the rules of liability prescribed by the legal system. While Schwartz focuses on the discovery of information, this paper focuses more on its communication.

In Section II I discuss a rule imposing liability for the harm caused by warnings that are too lax relative to an ideal warning. This rule can be cast in the language of negligence or strict liability. The material implications of the rule are the same, regardless of the choice of words, but in practice the words affect courts in ways that go beyond the rule's application.
\end{abstract}

\footnotetext{
* Professor of Law, University of California, Berkeley. Helpful comments were provided by my colleagues Steve Sugarman and John Fleming and several participants in the conference, including Guido Calabresi, Alvin Klevorick, William Landes, and Alan Schwartz.
}

[Journal of Legal Studies, vol. XIV (December 1985)] 
Section III defines efficient warnings and shows that the rule discussed in Section II-liability for the harm caused by lax warnings-causes warnings to be efficient. In contrast, a rule of "absolute liability," which holds the manufacturer liable for all dangers, remote and proximate, regardless of the level of care or the severity of the warning, will cause warnings to be too strong.

Section IV concerns insurance and bankruptcy. A manufacturer can externalize risk by going bankrupt in the event of a mass tort claim, so insurance should be encouraged to overcome this problem. Following Schwartz, I show that the doctrine of successor liability increases the amount of insurance purchased by firms against tort liability, which is in turn desirable from an efficiency perspective. In addition, a counterintuitive result is proved: capping manufacturer's legal liability can actually lead to an increase in the amount of insurance purchased.

The key propositions in the text are proved in a mathematical appendix on file with the journal and available from the author on request. ${ }^{1}$

\section{Framework}

Some beneficial products are inherently dangerous. The danger can be represented by a probability distribution over accident losses. Figure 1 represents the relationship between the probability of a loss from an accident and its magnitude in dollars for two different products. As depicted, the most probable event is "no accident," in which case the loss is nil. The downward slope to the curves indicates that, for these products, the probability of an accident diminishes as its severity increases. As depicted in Figure 1, a serious accident is more likely with product $B$ than with product $\mathrm{A}$, so $\mathrm{B}$ is more dangerous than $\mathrm{A} .^{2}$ For purposes of theory, the warning issued by the manufacturer of an inherently dangerous product can be thought of as a statement concerning the ranking of the product along a single dimension of product safety, as depicted in the figure.

A reasonable consumer will not use a product unless the expected benefits of use outweigh the inherent risks. The manufacturer's warning is one of the consumer's sources of information concerning the product's

\footnotetext{
1 School of Law, Boalt Hall, University of California, Berkeley, California 94720.

2 In general, one product is more dangerous than another if the curve of the more dangerous product can be obtained from the curve of the less dangerous product by shifting probability density to the right in Figure 1. One curve can always be obtained from the other by shifting density to the right if the curves for the two products do not intersect more than once. If the curves of the products intersect several times, then neither is unambiguously more dangerous than the other. Thus the ranking of products along a single dimension of dangerousness is partial, not complete.
} 


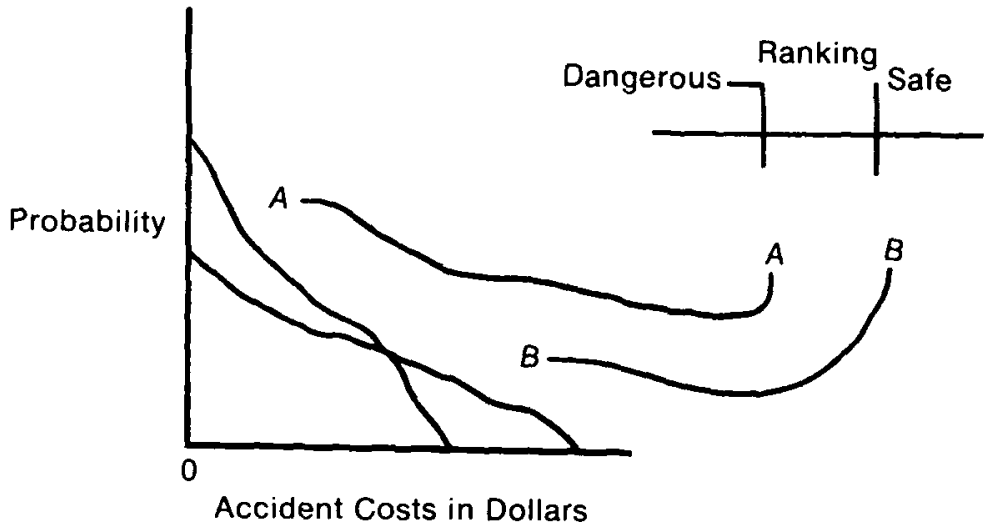

Figure 1.-Safety of product

dangerousness. When warnings are effective, a stronger warning causes fewer consumers to buy the product, and those who do take more precaution; conversely, a weaker warning causes more consumers to use it and to take less precaution. Consequently, the accident costs caused by an inherently dangerous product, whose dangerousness is held constant, will diminish with the strength of the warning, and a reasonable warning will avert some, but not all, harms to consumers.

This relationship between the warning and accident losses is depicted in Figure 2. In this figure the inherent dangerousness of the product is constant, so the extent of accident losses is determined by the extent of the

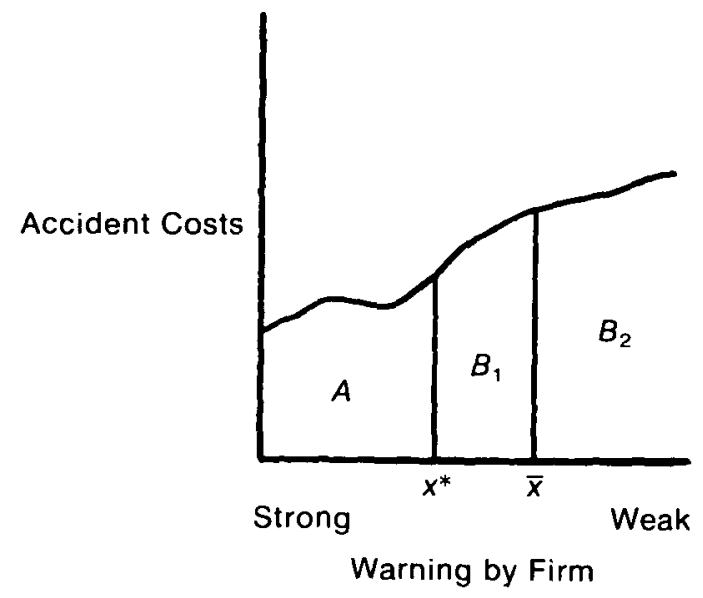

FIGURE 2.-Failure to warn 
product's use and the care with which it is used; and these in turn depend on the strength of the warning. The strength of the warning is shown on the horizontal axis, and accident costs are shown on the vertical axis. Moving to the right, accident costs rise as the warning becomes weaker. ${ }^{3}$

\section{Liability for INADEQUATE WaRnings}

A possible legal rule is to hold the manufacturer liable for the harm caused by inadequate warnings. For purposes of illustration, assume that $x^{*}$ in Figure 2 represents the ideal warning. (I postpone until later a discussion of the standard with respect to which $x^{*}$ is ideal.) If the manufacturer issues this warning, the accident costs that lie to the right of $x^{*}$, labeled areas $B_{1}$ and $B_{2}$, will be averted. In contrast, an ideal warning will not avert the accident costs that lie to the left of $x^{*}$, labeled area $A$ in Figure 2. Averting the accident costs corresponding to area $A$ would require a warning that is too strong because it drives away customers who should ideally use the good. Going to the opposite extreme, a warning like $\bar{x}$ is too weak because it attracts consumers who ideally should not use the good, and this results in excessive injuries, denoted by area $B_{1}$.

A rule that holds sellers liable for accidents attributable to a lax warning can be described in either of two ways. First, a lax warning can be described as a negligent act - the failure of the manufacturer to observe his duty to warn. Second, a lax warning can be described as a defective consumer product - the producer is held strictly liable for the injuries caused by the warning's inadequacy. The two verbal formulations are materially equivalent because the scope of responsibility and the extent of liability are the same: the manufacturer is only responsible when the warning is too weak, and his liability is limited to the harm that an ideal warning would have averted. Thus the warning $\bar{x}$ in Figure 2 can be described as negligent or as defective, but in either case liability corresponds to the area $B_{1}$, which represents the injuries that the warning $x^{*}$ would have averted.

Another question of language concerns whether to describe the rule portrayed in Figure 2 as limiting liability to harms that are proximately caused by lax warnings or as including remotely caused harms. The harms represented by $B_{1}$ can be called "proximate" because an adequate warning would have averted them, whereas the harms represented by $A$ can be called "remote" because they would occur even if the warning were

\footnotetext{
${ }^{3}$ Technically, the height of the curve in Figure 2 indicates the marginal loss from accidents as the warning varies, and the area under the curve (integral) indicates the total losses from accidents.
} 
adequate. Thus the rule of liability represented by the figure may be taken to restrict liability to harms proximately caused by lax warnings.

\section{Ex Ante and Ex Post Standards}

So far I have discussed the ideal warning $x^{*}$ as if it were known by the manufacturer. In reality, an investment of costly resources is usually required to discover the inherent dangers of a product. As Schwartz argues, the level of information about the product's dangers is efficient when the expected social benefit from further investment in research equals its cost. Sometimes the expected social benefit from further research is different from the actual benefit as discerned after the passage of time. To illustrate, it is now clear that the actual benefit from research on the connection between asbestos and lung cancer has been larger than most experts forty years ago believed it would be. Consequently, there is a distinction between ex ante efficient research, which appeared optimal relative to what was known at the time, and ex post efficient research, which proved optimal relative to subsequently discovered facts.

A similar distinction can be made for warnings. A warning is ex ante efficient if it is optimal relative to the information obtained from an ex ante efficient level of research; a warning is ex post efficient if it is optimal relative to the information obtained from ex post efficient research. Thus an ex ante efficient warning appears best prospectively, whereas an ex post efficient warning proves best retrospectively. To illustrate by Figure 2 , interpret $\bar{x}$ as the ex ante efficient warning, and interpret $x^{*}$ as the ex post efficient warning; in this case $B_{1}$ represents the accident costs caused by the prospectively best warning and averted by the retrospectively best warning.

For purposes of assigning liability, the ex ante and ex post standards for the adequacy of warnings are different, but, regardless of which standard is adopted, negligence and strict liability are materially equivalent verbal formulations: liability for the harm caused by an ex ante (ex post) unreasonable warning can be described as strict liability for the harm caused by an ex ante (ex post) defective warning.

This is not to say that there is nothing in a name. Negligence may carry with it a higher burden of proof and a broader array of defenses than strict liability. In addition, an allegation of negligence carries with it imputations of fault that are not present under strict liability. In an area in which conscious choice is present, a finding of fault becomes the opening wedge for punitive damages. Moreover, finding fault in a warning judged by an ex post standard amounts to blaming a manufacturer for not knowing the future. Hindsight may be an exact science, but prophecy is religion. If 
courts insist on holding manufacturers liable for being bad prophets, they ought not to be blamed for it, so the phrase "ex post defective warning", should be used instead of "ex post negligent warning."

\section{Efficiency, Absolute Liability, And Liability FOR INADEQUATE W ARNINGS}

The preceding section described a rule of liability for the consequences of inadequate warnings. Alternatively, the manufacturer might be held absolutely liable for all the harm caused by the use of his product, regardless of the warning that he gives to buyers. I will show that under plausible assumptions a rule of liability for inadequate warnings is more efficient than a rule of absolute liability. Specifically, in order for a rule of absolute liability to induce efficient warnings, both producer's liability and victim's compensation must be perfect. In contrast, a rule of liability for inadequate warnings induces efficient warnings if the standard of adequacy is correctly set, even though liability and compensation are imperfect. Proving these propositions requires a detailed explanation of consumer behavior, producer behavior, and efficiency.

\section{Consumer Behavior.}

When a consumer buys an inherently dangerous good, he pays a price to obtain it, he enjoys its intrinsic value, and he may make expenditures on safety precautions when using it. In so far as the intrinsic value exceeds the price and the cost of precaution, the buyer enjoys an immediate net benefit from the transaction. However, he exposes himself to the risk of consequential losses because he may be injured by the product. In the event of injury, he may receive damages. To the extent that the damages do not fully compensate him, there is risk of uncompensated harm. Using economic jargon, the elements of value affecting consumers are

$$
\begin{aligned}
& \text { consumer surplus }=\text { willingness to pay }- \text { price }- \text { precaution } \\
& \text { (immediate net benefits) } \\
& \text { - risk of uncompensated harm. } \\
& \text { (risk) }
\end{aligned}
$$

Since potential consumers differ according to their propensity to be harmed and according to their ability to benefit from the good, they can be ranked according to the extent of the anticipated consumer surplus from buying the good. To aid visualizing, assume that each consumer either buys exactly one unit of the good or does not buy any of it. By definition, the marginal consumer is indifferent between buying the good and not buying it, so his expected consumer surplus is nil, or, equivalently, his 


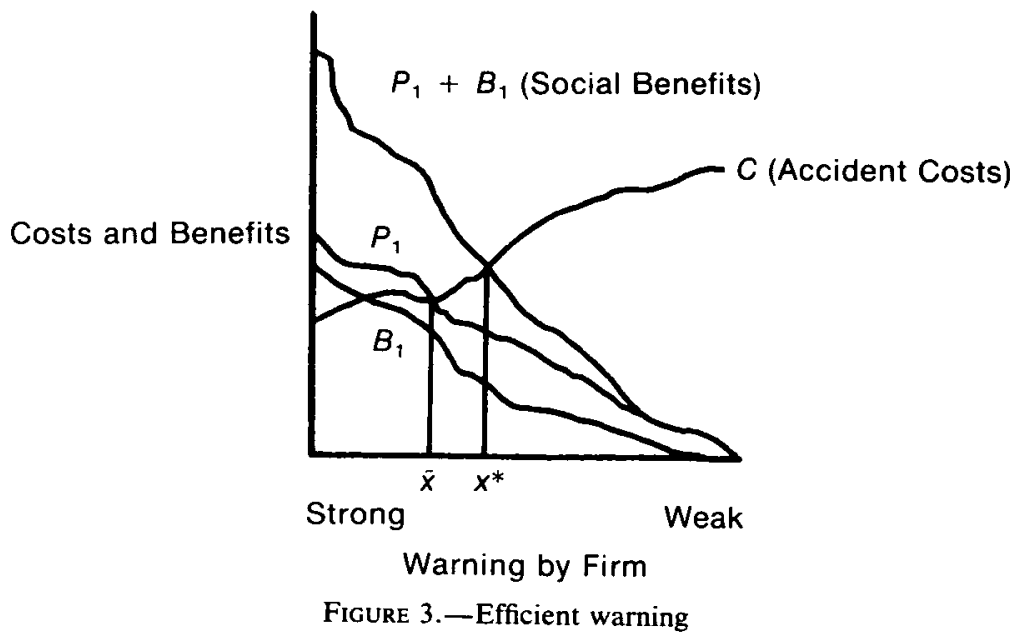

immediate net benefits equal his perceived risk. The marginal consumer represents the tipping point between users and nonusers. Every consumer ranked above the marginal consumer buys the good because he expects to enjoy positive surplus, and every consumer ranked below the marginal consumer does not buy it because he would expect negative surplus.

If consumers had perfect information about the inherent dangers of the product, perceived risk would equal actual risk. However, instead of having perfect information, consumers' beliefs about risk are influenced by the manufacturer's warning. If the warning is strong, a consumer will not buy unless his immediate net benefits from use are high relative to his propensity to be harmed. Thus the strength of the manufacturer's warning affects how far down in the ranking of consumers by immediate net benefits it is necessary to go before coming to the marginal buyer. The weaker the warning, the more consumers buy the good and the lower are the immediate net benefits of the marginal consumer, as represented by line $B_{1}$ in Figure $3 .^{4}$

\section{Behavior of Manufacturers}

Besides the consumer's surplus, the sale of the product generates profits for manufacturers. The manufacturer's immediate profit equals the

\footnotetext{
4 The height of the line $B_{1}$ indicates the immediate net benefits enjoyed by the marginal consumer at different levels of the warning, and the area under the curve (integral) indicates their sum. The downward slope of the curve reflects the fact that the immediate net benefits of the marginal buyer probably diminish as the waming becomes weaker, but the propositions explained in the paper (and proved in the mathematical appendix) are true even if it slopes up.
} 
difference between revenue from sales and the cost of production. A weaker warning by the firm attracts more buyers, and this increases immediate profits, as represented in Figure 3 by line $P_{1}{ }^{5}$ However, additional sales may give rise to additional tort liability, which must be netted out of immediate profits to give total profits:

$$
\begin{gathered}
\text { total profits }=\underset{\text { (immediate profits) }}{\text { revenue }- \text { production cost }}-\text { damages. } \\
\text { (liability) }
\end{gathered}
$$

A profit-maximizing firm will choose its warning by balancing immediate profits against liability; specifically, the warning is issued when the marginal immediate profit equals the marginal liability.

\section{Efficient Warnings and Absolute Liability}

The social benefits from the production and sale of the good equal the sum of the consumer's immediate net benefits and the manufacturer's immediate profits or, graphically, $B_{1}+P_{1}$ in Figure 3. Against these social benefits must be balanced the social costs of accidents indicated by line $C$ in Figure 3. Starting with a strong warning, efficiency requires weakening it until the social benefits curve $B_{1}+P_{1}$ intersects the accident cost curve $C$, yielding the efficient warning denoted $x^{*}{ }^{6}$

An efficient liability rule causes the profit-maximizing warning to equal the socially efficient warning. To compare the efficiency of the rule of absolute liability and the rule of liability for inadequate warnings, I need to introduce two technical terms. "Perfect liability" means that the damages paid by the injurer exactly equal the full cost of the harm suffered by the victim. If the damages equal the full cost of the harm suffered by the victim, but the victim must use part of the damages to pay lawyers and court costs, perfect liability results in undercompensation. Consequently, I use the term "perfect compensation" to mean that the injured consumer receives damages that exactly make him whole. I will show that absolute liability results in inefficient warnings unless there is both perfect liability and perfect compensation, whereas a rule of liability for inadequate warnings can result in efficient warnings even though liability and compensation are both imperfect. ${ }^{7}$

\footnotetext{
5 The height of $P_{1}$ indicates the marginal value of immediate profits, and the area under the curve (integral) indicates the sum of immediate profits.

6 There is an interesting relationship between efficient warnings and truthful warnings. If a consumer knew the full truth in detail concerning the hazards of using a product, he would not use it unless the expected benefits exceed the expected costs. As discussed in this paper, an efficient warning is a summary statistic that, when communicated to consumers, has the same effect as a truthful warning.

${ }^{7}$ In the usual tort models, the manufacturer's incentives for precaution are efficient under absolute liability when liability is perfect. See, for example, John Prather Brown. Toward an
} 
If the manufacturer is absolutely liable, and if liability is perfect, the liability cost curve in Figure 3 will be identical to the accident cost curve. Thus the manufacturer will find the profit-maximizing warning by equating immediate profits and accident costs (his liability) at the margin, which occurs at $\tilde{x}$ in the figure. Since $\tilde{x}<x^{*}$, the profit-maximizing warning is stronger than the efficient warning.

It is not hard to see why absolute liability results in warnings that are too strong. Recall that social benefits equal the sum of manufacturer's immediate profit and consumer's immediate net benefits. In choosing the warning, the manufacturer looks to his profits, not to effects on consumers. Consequently, for the manufacturer's self-interested behavior to be socially efficient, the marginal consumer's immediate net benefits must be nil so that social benefits and manufacturer's immediate profits are equal at the margin. As already explained, the marginal consumer equates the immediate net benefits to the risk of uncompensated harm, so the marginal consumer's immediate net benefits will be nil if there is no risk of uncompensated harm. For inherently dangerous products, there is no risk of uncompensated harm when compensation is perfect. Thus efficient warnings under a rule of absolute liability require perfect liability for producers and perfect compensation of injured consumers. Furthermore, when liability is absolute and perfect but compensation is imperfect, the producer's warning will be too strong relative to an efficient warning.

Perfect liability and perfect compensation are, however, seldom combined. First, compensation for personal injuries is so problematic in theory and practice that actual jury awards appear highly imperfect. Second, even if the jury awarded perfectly compensatory damages, a substantial portion of damages are soaked up by lawyers' fees and uncompensated court costs. Actual estimates indicate that tort cases yield to plaintiffs from 44 percent to 29 percent of the costs of the case. ${ }^{8}$ " When the pig of a tort claim is run through the python of the legal process, there is not much left for the accident victim." The consumer routinely faces the risk of uncompensated harm, and this results in warnings that are too strong.

This result can be explained in terms of externalities. When the manufacturer is absolutely liable for the full harm caused by his product, he

Economic Theory of Liability, 2 J. Legal Stud. 323 (1973). This is a much weaker condition than is required for efficient warnings as explained in this paper, specifically, perfect liability and perfect compensation.

8 These figures were supplied by Gary Schwartz (Directions in Contemporary Products Liability Scholarship, in this issue). His figures are obtained from studies of automobile insurance company records and records on asbestos litigation.

${ }^{9}$ This graphic phrase was used by Shelley McGovern at the conference that was the occasion for this paper. 


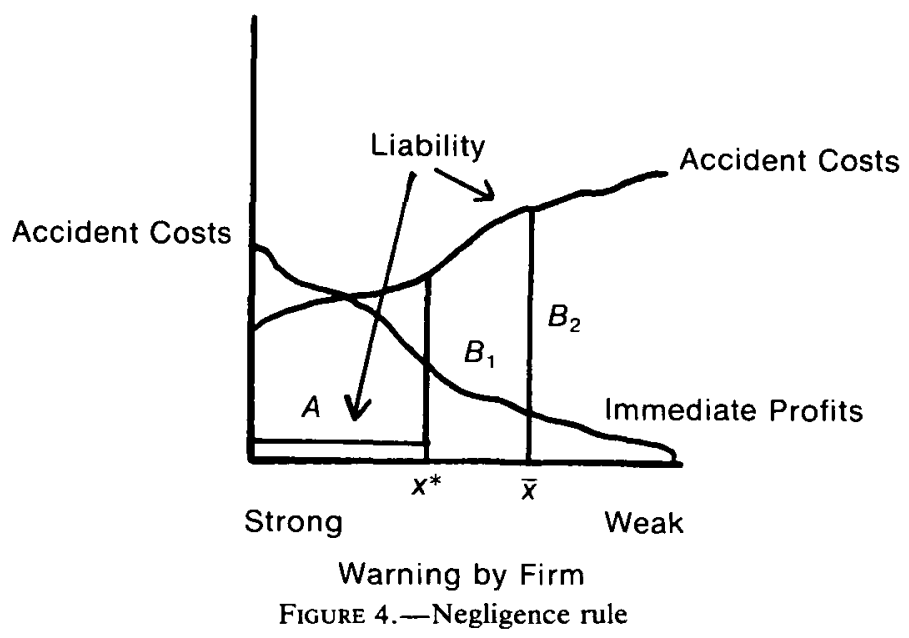

fully internalizes the risk of accidents. However, when the consumer is imperfectly compensated for accidents, he demands an immediate surplus from buying the good. The manufacturer does not internalize this element of social benefits. Since some social benefits of consumption are externalized by the firm, the profit-maximizing warning discourages more consumers than is socially efficient.

\section{Efficient Warnings and Liability for Inadequate Warnings}

A rule limiting liability to the harm caused by inadequate warnings overcomes this difficulty. Under such a rule, there is no liability until the warning crosses the threshold of inadequacy and becomes too weak, but once that threshold is crossed, the liability costs to the manufacturer jump sharply. The situation is depicted in Figure 4 where the arrows point to the line indicating the manufacturer's liability costs, which jump up at the legal standard $x^{*}$. The profit-maximizing manufacturer will choose his warning to avoid the zone in which his liability costs jump up; specifically, he will conform to the legal standard or slightly exceed it in order to allow for a margin of error by courts. Because the jump in costs is so precipitous, the manufacturer will continue to conform to the legal standard even if liability is imperfect in the sense that some costs are externalized. In general, if the legal standard is efficient, a rule of liability for inadequate warnings causes efficient behavior, even though some benefits are externalized as a result of imperfect liability and imperfect compensation. ${ }^{10}$

\footnotetext{
10 The foundation of this argument is explored more fully in Robert D. Cooter, Prices and Sanctions, 84 Colum. L. Rev. 1524 (1984).
} 
This point can be seen by examining Figure 4. To the left of the legal standard, immediate profits exceed liability, whereas to the right of the legal standard, liability exceeds immediate profits. Since the zone of profitability is where the immediate profit curve is higher than the liability curve, the profit-maximizing firm chooses the weakest warning at which his immediate profits are at least as large as his liability. Thus since the immediate profits curve intersects the liability curve at its discontinuity in Figure 4, the profit-maximizing warning equals the legal standard. This is true even if the social benefit curve lies moderately above the immediate profit curve or if the liability curve lies moderately below the accident cost curve.

From the viewpoint of allocative efficiency, the relevant legal standard is the ex ante measure. If the legal rule is liability for harm caused by ex ante inadequate warnings, the manufacturer's warning will maximize expected net social benefits. In contrast, the ex post standard will cause manufacturers to issue warnings that are too severe.

\section{Remarks}

Several remarks are in order about these conclusions. First, it is likely that manufacturers will escape legal liability in some instances due to imperfections in the legal system or that they will be found liable for damages from which some of the true costs of the accident are excluded by law. Under a rule of absolute liability, imperfect liability of manufacturers tends to cause warnings to be too weak, and, as explained, imperfect compensation of victims tends to cause warnings to be too strong. It is an empirical question which tendency is weightier.

Second, rather than considering incentives to innovate, my argument assumes that technology is unchanging. ${ }^{11}$ Absolute liability provides a constant pressure toward accident-reducing innovation by manufacturers. In contrast, insofar as the manufacturer escapes liability by issuing an adequate warning, he has little incentive to invest in innovations that would reduce accident costs. One way to overcome this problem is by applying the negligence standard to the investment in innovation so that a manufacturer is held liable unless he takes adequate efforts to discover unknown dangers and avoid them through redesigning the product. ${ }^{12}$

Third, unlike absolute liability, the rule of liability for inadequate warnings requires setting an efficient legal standard. Errors in setting the legal

\footnotetext{
1I A point stressed by Guido Calabresi at the conference.

12 Schwartz develops at length the argument that a negligence rule applied to investment in information about inherent dangers will be efficient.
} 


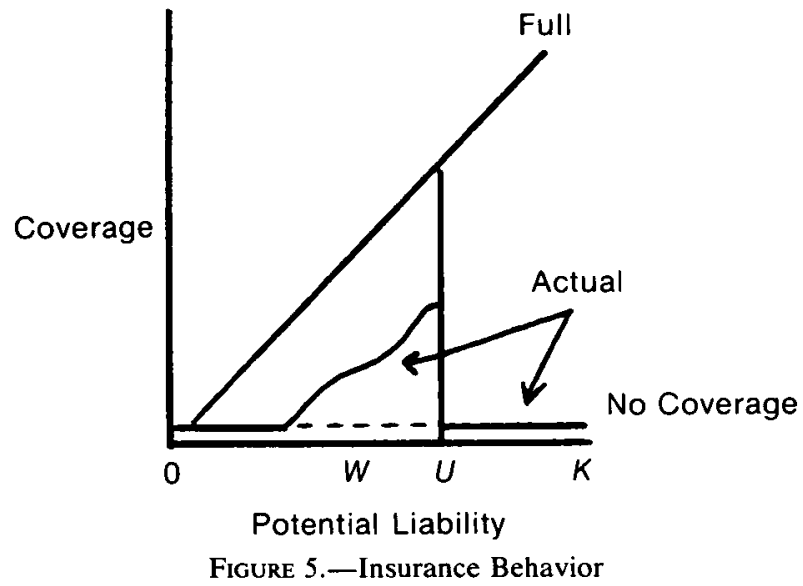

standard will disrupt the efficiency of this rule. To illustrate, if the legally required warning is weaker than the socially efficient warning, manufacturers will usually conform to the legal warning, not the efficient warning. This problem does not arise with absolute liability because it does not involve a legal standard. In view of this fact, the relative desirability of absolute liability and negligence depends on the kinds of errors that courts are inclined to make. On the one hand, if the courts are likely to make large errors in setting the legal standard for warnings, then absolute liability is preferable to negligence. ${ }^{13}$ On the other hand, if absolute liability exposes the consumer to a large risk of uncompensated harm, which will be the case when the transaction costs of dispute resolution are large, liability for inadequate warnings is superior to absolute liability.

\section{INSURANCE AND BANKRUPTCY}

Many firms do not insure enough to ward off bankruptcy or reorganization in the event of mass tort claims. Like the death of an individual, dissolution of a firm usually extinguishes tort claims that would arise in the future. Consequently, corporate reorganization and bankruptcy externalize some accident costs imposed by the firm's activities. The problem of cost externalization can be reduced by extending the insurance coverage of firms. Following Schwartz, this section concerns the legal policies that create incentives for more extensive insurance.

Figure 5 relates the amount of insurance to the magnitude of possible tort claims. Along the 45-degree line, insurance increases at the same rate

13 The risk of error in setting legal standards is large when courts must compute the efficient standard from industry data rather than relying on community standards. This point is stressed in Cooter, supra note 10. 
as tort claims, so this line represents full coverage. Along the horizontal axis, insurance remains nil as tort claims increase, so this line represents no insurance. An actual firm will usually not insure against small losses but will take policies with deductibles. The actual insurance line therefore corresponds to the no-insurance line for small tort claims. As the tort claim rises, the firm begins to purchase insurance, as depicted in Figure 5. However, most firms have an upper limit on their insurance coverage, so, when the possible tort claim becomes very large, the actual insurance line eventually drops down to the no-insurance line.

It is easy to see why most firms have an upper limit on insurance. Suppose that a decision maker has wealth equal to $\$ 100,000$ that he wishes to protect against liability claims, and suppose that the insurance premium is twenty-five cents per dollar of coverage. It costs $\$ 25,000$ to insure against a $\$ 100,000$ tort claim, $\$ 50,000$ to insure against a $\$ 200,000$ tort claim, and $\$ 100,000$ to insure against a $\$ 400,000$ tort claim. Just paying the premium on $\$ 400,000$ of coverage uses up his entire wealth, so it is not profitable to insure against losses that are this large. Better to run the risk of a suit than to use up all wealth to insure against it. Consequently, there is an upper limit on the coverage, short of $\$ 400,000$, that it is rational to buy.

In Figure 5, the slope of the actual insurance line represents the intensiveness of insurance, and the upper limit, denoted $U$, represents the extensiveness of insurance. As depicted, the upper limit $U$ occurs beyond the value of the decision maker's wealth $W$ and short of the largest possible tort claim $K$.

As Schwartz stresses, the risk of losses larger than $U$ is externalized. A problem for policymakers is to discover ways of extending $U$ farther to the right, reducing externalized risk. Two general types of policies will accomplish this result. First, increasing the amount of wealth $W$ at risk makes the safe strategy of insuring relatively more attractive than the risky strategy of not insuring, which pushes $U$ to the right. At least two legal devices extend the amount of wealth at risk. First, the amount of the decision maker's wealth that survives bankruptcy can be reduced. This end could be accomplished by narrowing the protection of personal wealth afforded by limited liability corporations. Second, as Schwartz notes, the scope of the successor doctrine can be expanded so that a new firm acquiring the assets of a dissolved firm also acquires the old firm's past and future tort liabilities. As a result, the new firm's entire wealth is potentially jeopardized by a tort claim. When the successor doctrine does not apply, corporate reorganization extinguishes some possible tort claims or shields the new firm's wealth from them.

Besides increasing the wealth in jeopardy, the second legal strategy for extending insurance coverage is to reduce liability for very large losses. 
Specifically, putting a cap on the upper limit of the firm's liability so that maximum liability is just above the firm's initial upper bound of insurance coverage will cause the firm to extend its coverage. To see why, let $K$ in Figure 5 represent the upper bound (cap) on liability. Capping liability at a value just above $U$ does not affect the expected utility of the risky strategy of not extending insurance beyond $U$ because, in spite of the cap, a liability claim anywhere in the range above $U$ forces the firm into bankruptcy. However, capping liability does increase the expected utility of the relatively safe strategy. Specifically, the cap increases the probability that an increase in insurance from $U$ up to the new value of $K$ will enable a firm to avoid bankruptcy brought on by tort claims. Since the cap causes the safe strategy to become relatively more attractive than the risky strategy, the upper bound of insurance coverage expands. ${ }^{14}$ In summary, moving $W$ to the right or moving $K$ to the left can in principle increase the extent of insurance.

Of course, capping liability will not increase the extent of insurance unless the right cap is used. In the preceding discussion, the cap occurred just beyond the firm's upper bound of insurance coverage. ${ }^{15}$ If the cap occurs below the firm's upper bound of insurance coverage, lowering the cap will reduce the extent of insurance coverage because there is no need to insure against losses for which the firm will not be liable.

\section{Conclusions}

In the absence of empirical tests of the propositions in this paper, my simple model is inadequate for making firm policy conclusions, but making some tentative conclusions is worthwhile. First, for inherently dangerous products the preferred rule is one that restricts liability to harm caused by inadequate warnings. The rival rule of absolute liability results in warnings that are too strong when consumers are exposed to the risk of uncompensated harm. Second, liability should not be extended to remote harms, that is, to those that could not be averted by an accurate warning. Third, negligence should be determined ex ante, on the basis of available information, and not ex post. Fourth, the bankruptcy and corporation law should be amended to make the extinction of tort claims more difficult in order to increase the level of insurance coverage and to reduce the risk of the externalization of harm.

\footnotetext{
14 This proposal is formulated and proved using a dynamic programming model in the mathematical appendix.

15 If the cap occurs well above the firm's upper bound of insurance coverage, the extent of his insurance will be unchanged.
} 